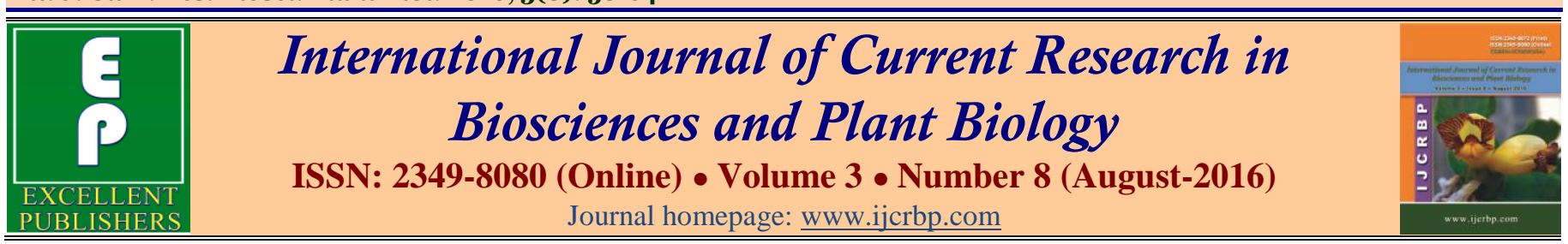

Original Research Article

doi: http://dx.doi.org/10.20546/ijcrbp.2016.308.009

\title{
Soil Type and Amendment Influence Growth and Yield of Tomatoes Lycopersicon esculentum L. in the Humid Mt Cameroon Region
}

\author{
P. M. Mfombep ${ }^{1}$, B. A. Fonge ${ }^{2 *}$, A. Atembe-afac ${ }^{2}$ and P. T. Tabot ${ }^{1}$ \\ ${ }^{1}$ Department of Agriculture, HTTTC Kumba, University of Buea, P.O. Box 249 Kumba, Cameroon \\ ${ }^{2}$ Department of Botany and Plant Physiology, Faculty of Science, University of Buea, P.O. Box 63 Buea, Cameroon \\ *Corresponding author.
}

\begin{abstract}
A b stract
Global demand for food, coupled with degrading soils in sub Saharan Africa necessitates novel approaches to soil fertility management. Recently, amendments other than inorganic fertilizers are being promoted to improve crop yield. They vary from region to region and crop to crop. The aim of this research was to investigate the efficacy of deep litter poultry manure as a soil amendment in tomato production in Cameroon. We tested the effects of poultry manure at $60 \mathrm{t} \mathrm{ha}^{-1}$ and NPK 20:10:10 at $300 \mathrm{~kg} \mathrm{ha}^{-1}$ in a Randomised Complete Block Design, with the treatment sites blocked by soil type. Classical growth parameters were measured weekly. Yield attributes were measured following harvest, and data submitted to RT ANOVA and Repeated measures ANOVA in the Minitab Version 16 statistical package. Both the organic and inorganic soil amendments increased growth and yield of tomato, but this effect was more significant in plots treated with poultry manure at $60 \mathrm{t} \mathrm{ha}^{-1}$ two weeks before planting. Growth effects were not clear-cut across sites and were probably mitigated by sitespecific differences in rates of nutrient-leaching. We recommend poultry manure at $60 \mathrm{t}$ $\mathrm{ha}^{-1}$ to small holder tomato farmers in the humid tropics.
\end{abstract}

\section{Introduction}

The increase in global population with its consequent increase in food consumption requires an increase in food production. However, the high demand for food, feed, fuel and fiber has resulted in diversified use of arable lands, thus reducing the cultivable land for food crops. The implication of this diversification in agriculture for Sub Saharan Africa (SSA) is that less land is available for food crop cultivation. In SSA this problem is compounded because, since 1979 food production has increased at half the rate of its population growth (Lal, 1997). This scenario is a call for concern because of poor and declining soil fertility in this region. Although mineral fertilizers are used to improve soil fertility, the fertilizer use is on average, less than $10 \mathrm{~kg}$ $\mathrm{ha}^{-1}$ compared to $87 \mathrm{~kg} \mathrm{ha}^{-1}$ used in developed nations (Bationo et al., 2006). Additionally, the nutrient losses from agricultural fields in SSA are higher than the regeneration rate. Therefore managing soil fertility in SSA has to integrate the best locally available and affordable soil fertility management strategies.

Integrated soil fertility management (ISFM) is especially important in production of vegetable crops which have short production cycles and require adequate supply of soil nutrients to improve crop productivity and ensure sustainable production. The ISFM is a set of agronomic practices adapted to local conditions to maximize nutrient use efficiency and sustainability (Ngosong et al., 2015). This is especially important for crops like Lycopersicon esculentum L. (tomato) with a short 
production cycle. Tomato is one of the most important vegetable crops grown throughout the world and ranks first as a processing crop (Mohammad et al., 2013). Its worldwide cultivation is also attributed to its food value, many uses, and relative ease of cultivation (Gory and Precheur, 2010). As a result, there has been an increase in the area of land cropped with tomato which led to increase in tomato production from 2009 to 2012 (FAOSTAT, 2013). The production in Cameroon for 2013 was 954,384 tons relative to the global production of 163,963.770 tons (FAOSTAT, 2013), constituting $0.6 \%$ of global production. These figures indicate the importance of tomato to the Cameroonian household and economy.

Early tomato gets ripe in less than 70 days after transplanting. They have a heavy nutrient uptake capacity and respond to soil nutrient amendments. The yield and quality from conventional and organic agriculture has been investigated (Polat et al., 2010) .The results indicate that agricultural inputs influence growth, yield and quality of tomato. The use of locally available inputs such as poultry litter which is available and easy to acquire could form part of the integrated soil fertility management required in tomato production. The current research assesses the use of ISFM on tomato production in Buea sub division, a major tomato production area. Buea is located on the slopes of Mount Cameroon, which has an altitudinal gradient. The soil is of volcanic origin but shows differences in soil composition and texture at different altitudes. In addition to inorganic soil amendment, different local organic materials, poultry litter, Tithonia, and Mucuna mulches have been used as soil amendment during tomato production in Buea.

The inclusion of poultry litter as a viable soil amendment for the Buea area is because there has been an increase in poultry production in Buea in recent years. Following the Cameroon government's ban on importation of frozen chicken, several local inhabitants began raising table birds on a commercial scale. This has increased the amount of poultry manure within the local communities. An analysis of poultry litter by Farhad et al. (2009) shows that on average poultry litter contains $2.04 \%$ Nitrogen (N), 2.06\% Phosphorous (P) and 86\% Potassium (K). However, research has shown that soil properties also influence tomato production and marketable yield (Moreno and Moreno, 2008). It is for this reason that this research seeks to assess the effect of both soil type and soil amendments on the growth and yield of tomato in the Mt Cameroon Region.

\section{Materials and methods}

The experiment was conducted in Buea sub division located on the eastern slope of Mount Cameroon between latitude $3^{\circ} 57^{\prime}$ to $4^{\circ} 27^{\prime} \mathrm{N}$ and longitude $8^{\circ} 58^{\prime}$ to $9^{\circ} 25^{\prime} \mathrm{E}$ with a mean annual rainfall of about $2800 \mathrm{~mm}$, received monthly between June and September (Egbe and Tabot, 2011). The mean annual temperature, relative humidity and sunshine are $28^{\circ} \mathrm{C}, 86 \%$ and 900 to $1200 \mathrm{hrs}$ per annum respectively (Egbe and Tabot, 2011). Buea is mountainous with thick evergreen forest vegetation and transitional changes along an altitudinal gradient. The soil type is basically volcanic (Cable and Cheek, 1998). The choice of experimental sites was based on an altitudinal gradient in areas where tomatoes are cultivated in Buea (Fig. 1). The selected sites were, Lower Farm, Molyko and Mamau.

Reconnaissance surveys were conducted to identify farmers who were cultivating tomatoes in these locations as well as their soil amendment practices. The experimental site for Molyko was within the research farm of the Department of Botany and Plant Physiology, at the University of Buea. Prior to this experiment, the site at Molyko was dominated by spear grass (Pinnesetum purpureum), cassava (Manihot esculentus), and maize (Zea mays). At Mamau and Lower Farm, tomato and maize had been grown continuously during the past cropping seasons. The intensive use of soil amendments by farmers in the cultivation of crops has been going on for more than 20 years in Lower Farm, more than 10 years in Molyko and less than 8 years in Mamau. Physical characteristics of soil used are presented in Table 1.

The experimental design was a randomized complete block (RCB) with three replications and three soil types. Five soil samples were randomly collected from each experimental site at $0-30 \mathrm{~cm}$ depth for soil analysis. There were four treatments comprising control (CT), poultry manure (PM), inorganic fertilizer (IF), combination of poultry manure and inorganic fertilizer (PI). The locations represented the different soil types. The hybrid tomato F1 Cobra 26; TECHNISEM ${ }^{\circledR}$ France was purchased from a local agro shop in Muea, Cameroon. The tomato seeds were pre-germinated in a nursery. Nursery beds were watered every evening for the first two weeks; thereafter watering was reduced to every other day until transplanting, which was done twenty five days after sowing. Planting holes of $70 \mathrm{~cm}$ between row and $60 \mathrm{~cm}$ within rows were pecked prior to application of experimental treatments. 


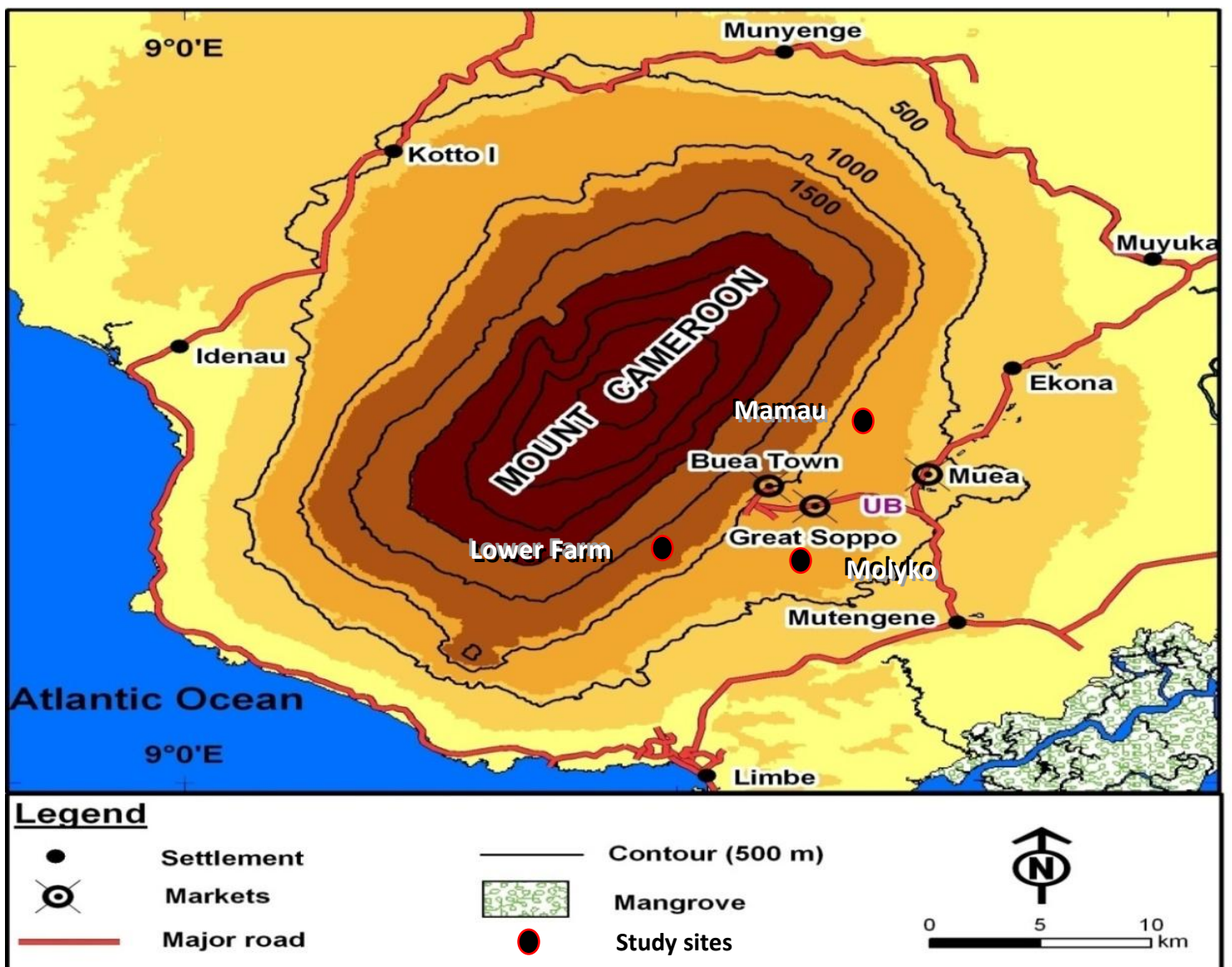

Fig. 1: GIS map of study area.

Table 1. Some physical and chemical characteristics of soils used $(0-30 \mathrm{~cm})$.

\begin{tabular}{llll}
\hline \multirow{2}{*}{ Soil characteristics } & Sites & & Molyko \\
\cline { 2 - 4 } & Mamau & Cow farm \\
\hline Texture & Sandy loam & 1.68 & Loam loam \\
Organic carbon $(\%)$ & 2.9 & 6.39 & 3.05 \\
Carbon/Nitrogen & 6.64 & 0.17 & 6.21 \\
Available N (mg/kg) & 0.48 & 10 & 0.24 \\
Available P $(\mathrm{mg} / \mathrm{kg})$ & 5 & 0.54 & 5 \\
Available K (mg/kg) & 0.23 & 5.63 & 0.17 \\
$\mathrm{pH}($ water) $1: 2: 5$ & 5.56 & 4.50 & 5.77 \\
pH (KCl) $1: 2: 5$ & 4.91 & 5.74 & 4.77 \\
CEC $(\mathrm{Cmol} / \mathrm{kg}$ & 4.87 & & 5.18 \\
\hline
\end{tabular}

Additionally, $2 \mathrm{~g}$ of insecticide (Morcarp) was placed in each of the pecked holes to reduce nematodes and other insect pests. Poultry manure was collected from a poultry farmer who uses a deep litter system. The manure was air dried, crushed to pass through a $2 \mathrm{~mm}$ sieve. The poultry manure was incorporated into the pecked holes at $60 \mathrm{t}$ ha ${ }^{1}$ two weeks before transplanting. Inorganic fertilizer, NPK 20:10:10 (ADER ${ }^{\circledR}$ Cameroon) was applied as side placement at $300 \mathrm{~kg} \mathrm{ha}^{-1}$. The inorganic fertilizer was applied in two split applications. The first application was at two weeks after transplanting while the second was at 4 weeks after onset of flowering. The same procedures were used when the combined poultry manure and inorganic fertilizer was applied. The experimental plots were watered three times a week during the first three weeks but discontinued at the onset of the rainy season. Weeding was done as required by hand. The management of pest and diseases was done using fungicide (Mancozan super, SCPA SIVEX international ${ }^{\circledR}$ France) while insecticide (Garmaline 80, AGROMAF® Cameroon; Cigogne 360, SCPA SIVEX International ${ }^{\circledR}$ France andAcarius, SAVANA-Horizon 
PhyoPlus ${ }^{\circledR C a m e r o n n)}$ were used for insect control. These cultural practices were uniform for all the treatments. All laboratory analysis was done at the Soil and Plant Science Laboratory of the University of Dschang, Cameroon. The different biometric observations were recorded from plants within a $3 \mathrm{~m} \mathrm{x}$ $3 \mathrm{~m}\left(9 \mathrm{~m}^{2}\right)$ area marked out in the middle of each plot on a weekly basis. Yield and related parameters were determined after harvest.

Data was analysed using repeated measures of Analysis of Variance (ANOVA). The main effects include fertilizer (organic and inorganic), time and sites (blocks). Main and interaction effects were assessed through GLM ANOVA with interactions, following tests for normality and homogeneity of variance. Data that did not meet conditions of normality and homogeneity of variance were either subjected to Johnson transformation or Ranked transformed, prior to ANOVA. Turkey test was used to separate treatment means and statistics were done at $\alpha=0.05$.

\section{Results}

The soil analysis showed that the soils were sandy loam at Mamau, clay loam at Molyko and loam at Lower Farm and the soil $\mathrm{pH}(\mathrm{KCl})$ at all sites was acidic (Table 1). Across sites (Data not shown), the soil amendments and their interaction significantly increased height, leaf length, number of leaves and collar diameter $(p=0.000)$. The impact of soil amendments on plant height differed by location (Fig. 2).

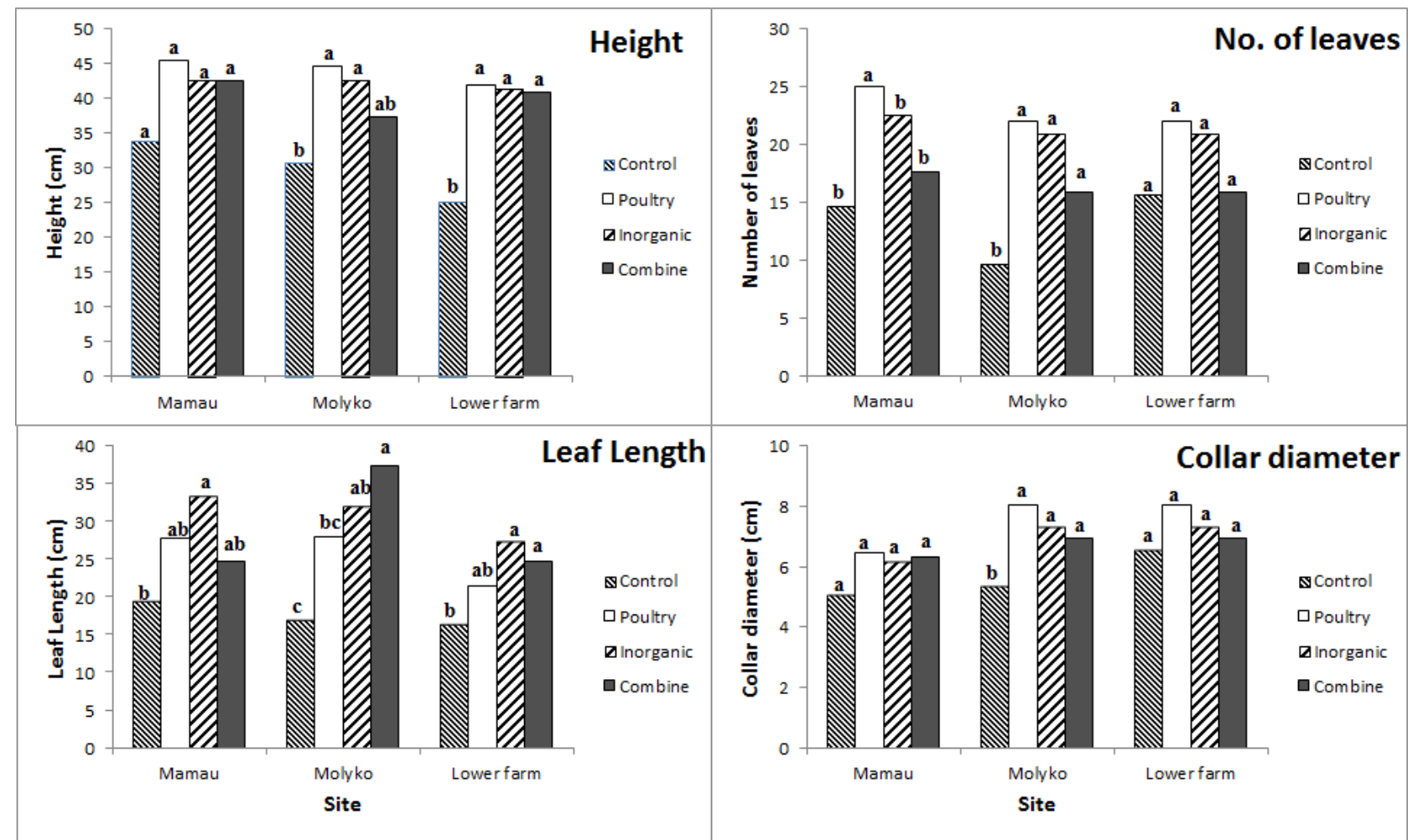

Fig. 2: Interaction of soil type (location) and soil amendment on growth parameters (Height, number of leaves, leaf length, collar diameter) of tomato. Bars represent means. Means separated by GLM ANOVA at $\alpha=0.05$. Means followed by the same letter(s) for each site are not significantly different.

The addition of poultry manure and inorganic fertilizer increased plant height relative to the control at Molyko, while at Mamau, there were no differences between the nutrient added plots and control. At Lower Farm, all soil amendments increased plant height relative to control. The effect of soil amendment on number of leaves showed that poultry manure increased the number of leaves at Mamau while it was increased by all treatments at Molyko relative to control, with no effect at Lower Farm. The leaf length was increased at Molyko by the combined poultry litter and inorganic fertilizer but, it was increased by inorganic fertilizer at Mamua, by both inorganic and the combination of inorganic and poultry litter at Lower Farm. It was only at Molyko that all treatments increased collar diameter relative to control. 
Analysis of Variance results showed that all soil amendments increased yields and the number of baskets of tomato across sites, with the best yields recorded from plots treated with poultry manure (Table 2; Fig. 3). Yields ranged from $27.6 \mathrm{t} / \mathrm{ha}$ in the plots treated with a combination of poultry manure and inorganic fertilizer treatments to 40.3 t/ha in plots treated with poultry manure only, compared to just 8.5 t/ha in the control plot where no soil amendments were done. However the weight per basket was similar across sites irrespective of treatment (Fig. 3).

Table 2. Effect of organic and inorganic fertilizers on yield attributes at all sites.

\begin{tabular}{|c|c|c|c|c|c|c|}
\hline \multirow[b]{2}{*}{ Soil amendments } & \multicolumn{6}{|l|}{ Sites } \\
\hline & \multicolumn{2}{|l|}{ Mamau } & \multicolumn{2}{|l|}{ Molyko } & \multicolumn{2}{|c|}{ Lower farm } \\
\hline Control & $32.94 \mathrm{a}$ & $17.22 \mathrm{~b}$ & $37.53 b c$ & $15.41 \mathrm{~b}$ & $28.14 \mathrm{a}$ & $16.46 \mathrm{a}$ \\
\hline Inorganic fertilizer & $44.54 \mathrm{a}$ & $26.69 \mathrm{ab}$ & $45.48 \mathrm{ab}$ & $29.39 a$ & $32.81 \mathrm{a}$ & $20.14 a$ \\
\hline Combined & $37.03 \mathrm{a}$ & $16.61 b$ & $33.48 \mathrm{c}$ & $20.02 \mathrm{ab}$ & $29.50 \mathrm{a}$ & $11.14 \mathrm{a}$ \\
\hline
\end{tabular}

Values represent means. Means separated by GLM ANOVA at $\alpha=0.05$; Means followed by the same letter(s) in a column are not significantly different; NFS: Number of fruit sets; NF: Number of fruits; CT: Control; PM: Poultry manure; IF: Inorganic fertilizer; PI: Poultry manure and inorganic fertilizer.

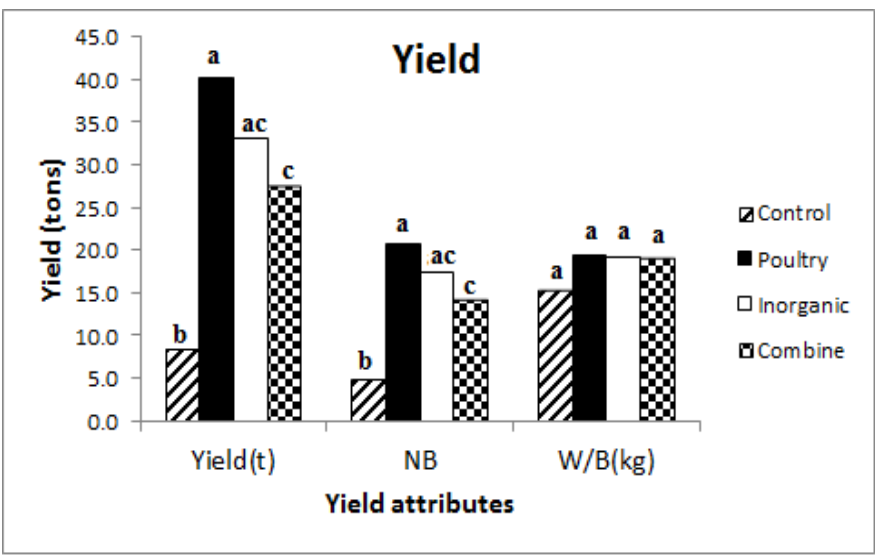

Fig. 3: Effect of soil amendment on tomato yield attributes. Bars represent means. Means separated by GLM ANOVA at $\alpha$ $=0.05$. Means followed by the same letter(s) for each attribute are not significantly different. $\mathrm{NB}=$ number of baskets; $\mathrm{WB}=$ fruit weight per basket. One basket had a volume of approximately $15 \mathrm{~L}$.

The inorganic and organic fertilizer and their interaction significantly $(p<0.05)$ affected number of fruits and number of fruit sets in Mamau and lower Farm. The highest number of fruit sets (50) was obtained from plants treated with poultry manure at Molyko. The highest number of fruits (30) was obtained from plants treated with poultry manure at Mamau while the least (11) was obtained from plants treated with combined poultry manure and inorganic fertilizer at Lower Farm. Fruit characteristic data across sites showed that the largest fruit diameter $(14.4 \mathrm{~cm})$ was from plants treated with inorganic fertilizer.

The longest fruits $(7.16 \mathrm{~cm})$ were from plants treated with both organic and inorganic fertilizer.

\section{Discussion}

The physical and chemical degradation of cultivated land is due to poor and inappropriate management. Soil degradation is the most serious environmental problem affecting sub-Sahara Africa (Nabhan et al., 1999). Soil organic matter represents a key indicator for soil quality, both for agricultural (production and economy) and environmental functions. The aim of increasing crop production is to meet population demand for food, which in SSA is mainly undertaken by small holder farmers. These producers require the best information possible to enhance the declining soil fertility which affects their crop production capability. Improving soil fertility by using the available local resources will not only reduce current cost of production (when inorganic fertilizer is purchased), but will increase crop production per unit area.

The increase in tomato production in the manure-applied plots across all sites in this study can be attributed to the method of application. When manure is incorporated into the soil, it reduces $\mathrm{NH}_{3}$ volatilization (Havlin et al., 2005). Additionally, the poultry manure contains other elements which include $\mathrm{Ca}$ and $\mathrm{Mg}$ in addition to $\mathrm{N}, \mathrm{P}$, and $\mathrm{K}$, unlike the inorganic fertilizers (mostly available to farmers) which contain basically $\mathrm{N}, \mathrm{P}$, and $\mathrm{K}$. The combined addition of poultry manure and inorganic fertilizer increased plant height. However, it was the application of poultry manure that increased tomato yields. The yield of tomatoes depends on both the soil and crop management practices. In spite of the $300 \mathrm{~kg}$ $\mathrm{ha}^{-1}$ inorganic fertilizer (NPK) application to the tomato, organic manure at 60 ton $\mathrm{ha}^{-1}$ produced more tomatoes 
than inorganic fertilizer across all locations. The results are consistent with findings by Mohammad et al. (2013) who reported significant increase in tomato yields in plots treated with poultry manure at 80 tonnes $\mathrm{ha}^{-1}$. The analysis of the poultry manure showed that it had high amounts of nutrients (organic carbon, total nitrogen, available phosphorus, $\mathrm{Na}, \mathrm{Mg}, \mathrm{K}$ and $\mathrm{Ca}$ ). Poultry manure improves soil biology while the woody mulch material holds water, and regulates temperature.

The higher production related to poultry manure may also be attributed to increased available soil nutrients, improved crop nutrient uptake as a result of increased soil biophysicochemical properties. The use of poultry manure in agriculture will not only increase crop and other biomass production, but will also serve to reduce environmental pollution from accumulation or dumping of poultry litter in the environment, or the eutrophication resulting from leaching of excess inorganic fertilizers into water bodies (Carpenter et al., 1998).

With an altitudinal gradient in Buea, the runoff is expected to be greater at Lower Farm hence, more loss of nutrients than Mamau, however, the results did not show differences in yield at both sites, except for differences in leaf length. This is indicative that the soil characteristics were not as major factors in tomato production compared to the soil amendments. Farmers do not have adequate access to inorganic fertilizer, hence nutrient amendment strategies need to be developed to address soil nutrition provision and adequate plant nutrition insurance. Only $16 \%$ of Africa's land is considered high quality whereas $55 \%$ is unsuitable for cultivated agriculture. However, this land is expected to support more than 900 million people. The cost of inorganic fertilizer is relatively high for farmers in SSA. Additionally, where they can afford it, the consequences of its use to the environment when excessively added to soils will be devastating to the fragile soils of tropical SSA as well as other ecosystems (Prasad, 1998; Carpenter et al., 1998). In the developed world, excessive fertilizer and manure application which resulted in increased productivity has damaged the environment, and the effects of inappropriate use of inorganic fertilizers are already felt in SSA. This is the reason why locally available alternative soil amendments like use of poultry manure solely or in combination with inorganic fertilizers is essential to enhance crop productivity.

This action will reduce the conversion of forests and reserved areas for agricultural purposes. Lack of volcanic rejuvenation has been cited as one cause of poor African soils (Smaling and Braun, 1996), however, the soils in Buea are of volcanic origin and have been considered as relatively fertile. In spite of this, excessive cultivation on these soils without replenishment leaves them nutrientdepleted. However, inorganic fertilizer use is not the only means to improve agricultural production. Organic inputs and resources are able to sustain agricultural production in most areas. The use of organic inputs such as Tithonia and Mucuna mulches has been shown to be beneficial in tomato production (Ngosong et al., 2015). Some studies have advocated the use of both inorganic and organic soil amendments to increase outputs during crop production. However, our research indicated that combining both inorganic and organic amendments did not increase yields as much as the organic amendment alone, consistent with findings by others authors (e.g. Fonge et al., 2016 on leafy vegetables; Prasad et al., 2016 on Lagenaria siceraria). Organic inputs have added advantage of stimulating soil biological activities, which are useful in recycling nutrients in soil organic matter. They are renewable, and not as easily leached as inorganic fertilizers because they release nutrients slowly. Another element which influences crop production which involves inorganic fertilizer application, is the nature of these soils. These soils are also susceptible to the heavy rainfall regime of the region which is compounded by the sloppy nature of the terrain. Leaching of nutrients from these soils will be faster with inorganic amendments than organic manure and expected to be different for the different locations due to differences in their particle size distribution. These properties might be responsible for the varying results obtained for the growth parameters with the different amendments at each of the locations. There are soil fertility gradients in the field which affect crop production even in the same field (Prudencio, 1993). These gradients are likely to also influence the crop response to inorganic and organic fertilizer applications at different locations within the same area.

\section{Conclusion}

The poultry manure which was incorporated into the soil two weeks prior to transplanting produced higher yields across sites. The implication is that application of poultry manure effectively synchronized the crop's demand for-, and supply of nutrients. Therefore the use of poultry litter has the potential to be recommended in smallholder tomato production farms in the Buea region irrespective of specific locations. Although this recommendation is a specific needs relieve for smallholder farmers, this approach may not be efficient for larger scale producers 
because of the bulkiness of poultry manure and other environmental issues associated with handling poultry manure on a large scale.

\section{Conflict of interest statement}

Authors declare that they have no conflict of interest.

\section{Acknowledgement}

The authors thank all farmers who provided fields for this research. We acknowledge the assistance of Mrs Fonge of the University for Dchang for soil nutrients analyses.

\section{References}

Bationo, A., Hartemink, A., Lungu, O., Naimi, M., Okoth, P., Smaling, E., Thiombiano, L., 2006. African Soils: Their Productivity and Profitability of Fertilizer Use. Proceedings of the African Fertilizer Summit, Abuja, 9-13 June 29.

Cable, S., Cheek, M., 1998.The Plants of Mt Cameroon -A Conservation Check List. RBG Kew, London. 19pp.

Carpenter, S.R, Caraco, N.F., Howarth, R.W., Sharpley, A.N., Smith, V.H., 1998. Nonpoint pollution of surface waters with phosphorus and nitrogen. Ecol. Appl. 8(3), 559 568.

Egbe, E.A., Tabot, P.T., 2011. Carbon sequestration in eight woody non-timber forest species and their economic potentials in Southwestern Cameroon. Appl. Ecol. Environ. Res. 9(4), 369-385.

FAOSTAT, 2013. Food and Agriculture Organization Statistics (FAOSTAT). Retrieved from http://faostat3.fao.org

Farhad, W., Saleem, M.F., Cheema, M.A., Hammad, H.M., 2009. Effect of poultry manure levels on the productivity of spring maize (Zea mays L.) J. Anim. Plant Sci. 19 (3), 122-125.

Fonge, B.A., Bechem, E.E., Awo, E.M., 2016. Fertilizer rate on growth, yield, and nutrient concentration of leafy vegetables. Int. J. Veg. Sci. 22(3), 274-288.

Gory, G., Precheur, B., 2010. Growing tomato in the home garden. J. Agric. Nat. Resour. (1), 2-11.

Havlin, J.L., Beaton, J.D., Tisdale, S.L., Nelson, W.L., 2005. Soil Fertility and Fertilizers: An Introduction to Nutrient Management. $7^{\text {th }}$ Edn. Pearson Prentice Hall, Upper Saddle River, NJ.

Lal, R., 1997. Degradation and resilience of soils. Philos. Trans. R. Soc. B. 352, 997-1010.

Mohammad, M., Ebrahim, I., Darbandi, H.N., Ahmad, T., 2013. Growth and yield of tomato (Lycopersicon esculentum Mill.) as influenced by different organic fertilizers. Int. J. Agron. Plant Prod. 4(4), 734-738.

Moreno, M.M., Moreno, A., 2008. Effect of different biodegradable and polyethylene mulches on soil properties and production in a tomato crop. Sci. Hortic. 116(3), 256-263.

Nabhan, H., Mashali, A. M., Mermut, A. R., 1999. Integrated Soil Management for Sustainable Agriculture and Food Security in Southern and East Africa. Proceedings of the Expert Consultation, Harare, Zimbabwe. 8-12 December 1997. Food and Agriculture Organization of the United Nations, Rome. 405p.

Ngosong, C., Mfombep, P.M., Njume, A.C., Tening, A.S., 2015. Integrated soil fertility management. integrated soil fertility management: Impact of Mucuna and Tithonia biomass on tomato (Lycopersicon esculentum L.)Performance in smallholder farming systems. Agric. Sci. 6, 1176-1186.

Polat, E., Demir, H., Erler, F., 2010. Yield and quality criteria in organically and conventionally grown tomatoes in Turkey. Sci. Agric. 67(4), 424-430.

Prasad, G., Nandi, A., Swain, P.K., 2016. Soil amendment and integrated nutrient management on growth, yield, soil health, and economics of bottle gourd. Int. J. Veg. Sci. 22, 3-13.

Prasad, R., 1998. Fertilizer urea, food security, Health and the environment. Curr. Sci. 75(7), 677-683.

Prudencio, C.Y., 1993. Ring management of soils and crops in the West African semi-arid tropics: the case of the Mossi farming system in Burkina Faso. Agric. Ecosyst. Environ. 47, 237-264.

Smaling, E.M.A., Braun, A.R., 1996. Soil fertility research in Africa: New dimensions, new challenges. Commun. Soil Sci. Plant Anal. 27(3-4), 365-386.

\section{How to cite this article:}

Mfombep, P. M., Fonge, B. A., Atembe-afac, A., Tabot, P. T., 2016. Soil type and amendment influence growth and yield of tomatoes Lycopersicon esculentum L. in the humid Mt Cameroon Region. Int. J. Curr. Res. Biosci. Plant Biol. 3(8), 58-64. doi: http://dx.doi.org/10.20546/ijcrbp.2016.308.009 